\title{
Characterization of Fusarium Root Rot Isolates from Sugar Beet by Growth and Virulence at Different Temperatures and Irrigation Regimes
}

\author{
R. M. Harveson, Department of Plant Pathology, University of Florida, P.O. Box 110680, Gainesville 32611, and \\ C. M. Rush, Texas A\&M University System, Texas Agricultural Experiment Station, P.O. Drawer 10, Bushland \\ 79012
}

\begin{abstract}
Harveson, R. M., and Rush, C. M. 1998. Characterization of Fusarium root rot isolates from sugar beet by growth and virulence at different temperatures and irrigation regimes. Plant Dis. $82: 1039-1042$.

Fusarium root rot, caused by Fusarium oxysporum f. sp. betae is one of several root diseases damaging to sugar beet production in Texas. As a primary symptom, most isolates produce a severe tip rot on the distal end of the taproot, in addition to discoloration of vascular elements and wilting. Tip rot distinguishes Fusarium root rot from another $F$. oxysporum f. sp. betaeincited disease, Fusarium yellows, which induces vascular discoloration and wilting but no root rot. This study was conducted to further characterize a selection of five Texas $F$. oxysporum $\mathrm{f}$. sp. betae isolates representing different vegetative compatibility groupings, symptom types (tip rot, and non-tip rot), and hosts. Radial growth at six temperatures was measured for each isolate in culture on half-strength potato dextrose agar. Significant growth differences were detected, indicating a substantial amount of variation among the isolates. Virulence of isolates was evaluated by inoculating 6-week-old sugar beet plants with a microspore suspension and transplanting them into infested field soil. The plants were incubated at 20 and $30^{\circ} \mathrm{C}$ in controlled temperature boxes within the greenhouse and grown under two different irrigation schedules. After 6 weeks, plants were harvested and assigned a root disease rating, and root and foliar dry weights were determined. Disease ratings among isolates at $30^{\circ} \mathrm{C}$ resulted in three isolates (all tip rot isolates) being severe, one mild, and one intermediate. At $20^{\circ} \mathrm{C}$, only one isolate caused appreciable root damage. Irrigation treatments had no effect on disease incidence or severity. Significant differences in colony diameter growth and virulence among isolates at the two temperatures provide further evidence of variation among Texas $F$. oxysporum f. sp. betae populations. Results also suggest that the tip rot phenotype may be induced by some genetic factor unique to tip rot isolates. Therefore, the form name $F$. oxysporum f. sp. radicis-betae is proposed for those isolates from Texas causing a tip rot.
\end{abstract}

Fusarium oxysporum Schlechtend.:Fr. emend. W.C. Snyder \& H.N. Hans. f. sp. betae Stewart, the causal agent of Fusarium root rot, is a major contributor to sugar beet yield losses in Texas. Fusarium root rot is one of several root diseases occurring in Texas in a complex that includes Rhizoctonia root rot, Aphanomyces root rot, and rhizomania (11), but its basic etiology is poorly understood. Fusarium root rot from Texas often is characterized by a severe tip rot, in addition to the wilting and vascular discoloration that are normally associated with diseases incited by $F$. oxysporum. This tip rot symptom is common to the disease in Texas but has seldom been observed in other sugar beet-growing locations. Isolates from Oregon and California were tested in greenhouse trials utilizing field soil and were not able to cause the

Corresponding author: C. M. Rush

E-mail: cm-rush@tamu.edu

Accepted for publication 12 June 1998.

Publication no. D-1998-0717-02R

(C) 1998 The American Phytopathological Society tip rot symptom, whereas those from Texas consistently did so (19).

In a recent study (12), the sugar beetgrowing regions of Texas were surveyed for $F$. oxysporum f. sp. betae, and isolates were analyzed for genetic variation by vegetative compatibility. It was found that isolates causing tip rot symptoms often formed heterokaryons in complementation tests with isolates not causing tip rot symptoms. This suggested that genes conferring vegetative compatibility are distinct from those associated with pathogenicity and that vegetative compatibility group (VCG) typing was incapable of distinguishing or identifying isolates causing the two major types of symptoms.

This same study also compared Texas isolates to those from a number of other sugar beet-growing states. It was determined that sugar beet isolates from the United States exhibited a substantial amount of variation based upon vegetative compatibility. No isolate from any one state was compatible with any other isolate from a different state (12). This confirmed results from previous studies using other techniques (random amplified polymorphic DNA, polymerase chain reaction, and isozyme analysis) that isolates from Oregon, California, Montana, Colorado, and Wyoming were genetically distinct from those in Texas $(8,19)$.

Although it has been demonstrated that $F$. oxysporum f. sp. betae isolates from Texas are genetically different from those from other states, it is still unclear as to the nature of the tip rot symptom. Therefore, this study was begun as a first step toward understanding the basis for the tip rot symptom type by characterizing a selected group of Texas isolates on the basis of their responses to different environmental conditions, including growth in culture at different temperatures and virulence at different soil temperatures and moisture levels. A preliminary report has been published (13).

\section{MATERIALS AND METHODS}

The five isolates used for this study were chosen based on a number of criteria. First, they represented examples of isolates previously used to establish the number of VCGs present among Texas isolates (12). This collection consisted of pathogenic isolates from both sugar beet and the closely related weed, red root pigweed (Amaranthus retroflexus L.). It also included isolates inducing both symptom types in addition to containing members of two distinct VCGs and one that was selfincompatible (Table 1).

Radial growth at different temperatures. Each isolate, started from a single spore, was grown on half-strength potato dextrose agar (PDA) and incubated in the dark at six temperatures, 10, 15, 20, 25, 30, and $35^{\circ} \mathrm{C}$. There were six replications for each temperature-isolate combination. Colony diameter measurements were recorded daily for 8 days, and the study was repeated once. Data were analyzed by analysis of variance, and means were separated by Duncan's multiple range test. No differences were observed between the two tests, and no treatment-test interactions occurred, so experiments were combined to give a total of 12 replications per isolate per temperature.

Virulence evaluations at two soil temperatures and irrigation schedules. This portion of the study was conducted in 10$\mathrm{cm}$-diameter PVC tubes within the greenhouse. Each tube, $25 \mathrm{~cm}$ in length, was sealed at one end, filled with field soil, and placed in a controlled temperature box 
(10). Temperature was regulated in the rhizosphere by refrigerated air and a heating coil wound around the bottom of the box (10), and monitored by thermometers placed in the upper $10 \mathrm{~cm}$ of tubes.

Field soil was infested with approximately 1,000 conidia per gram for each isolate and stirred with a commercial cement mixer prior to being placed in the PVC tubes. A previous study under similar conditions found that colony-forming units of $F$. solani $\mathrm{f}$. sp. pisi placed in the lower $10 \mathrm{~cm}$ of a $30-\mathrm{cm}$ container failed to cause any noticeable root rot to peas (21). However, if inoculum was placed in the upper $10 \mathrm{~cm}$ or mixed throughout the profile, significant reductions were observed in plant dry weights and heights compared with uninoculated controls (21). To ensure disease development in the present study, 4- to 6-week-old sugar beet plants (hybrid cultivar Ranger) were additionally rootdipped with a conidial suspension of $1 \times$ $10^{6}$ conidia per $\mathrm{ml}$ before being transplanted (one plant per tube) into the containers filled with infested soil. All tubes were watered equally prior to the addition of the inoculated plants.

Six treatments (five isolates plus deionized water-inoculated control), replicated six times, were included in this study. Treatments were completely randomized within each of two temperature boxes, held constant at 30 and $20^{\circ} \mathrm{C}$. Within each temperature box, plants inoculated with each isolate treatment were exposed to two irrigation regimes, one watered once weekly (low) and the other twice a week (high). This included 12 tubes per isolate, with six being wet and six being dry, for a total of 72 tubes (plants) for each temperature box. Irrigation was accomplished by a drip sys-

Table 1. Isolates of Fusarium oxysporum f. sp. betae selected for growth and virulence evaluations at different temperatures

\begin{tabular}{lccc}
\hline Isolate & Symptom $^{\mathbf{x}}$ & Source $^{\mathbf{y}}$ & VCG $^{\mathbf{z}}$ \\
\hline F5 & TR & B & SI \\
F44 & NTR & B & 1 \\
F125 & NTR & PW & 6 \\
F127 & TR & B & 1 \\
F156 & TR & PW & 1 \\
\hline
\end{tabular}

${ }^{\mathrm{x}} \mathrm{TR}=$ tip rot isolate, $\mathrm{NTR}=$ non-tip rot isolate.

${ }^{\mathrm{y}} \mathrm{B}=$ sugar beet, $\mathrm{PW}=$ pigweed.

${ }^{\mathrm{z}}$ Vegetative compatibility group; SI = self-incompatible.

Table 2. Radial growth of Fusarium oxysporum f. sp. betae isolates (mm) in culture at different temperatures after 8 days

\begin{tabular}{lcrcccc}
\hline & \multicolumn{7}{c}{ Temperature $\left({ }^{\circ} \mathbf{C}\right)$} \\
\cline { 2 - 7 } Isolate & $\mathbf{1 0}$ & $\mathbf{1 5}$ & $\mathbf{2 0}$ & $\mathbf{2 5}$ & $\mathbf{3 0}$ & $\mathbf{3 5}$ \\
\hline F5 & $3.3 \mathrm{bc}^{\mathrm{z}}$ & $8.6 \mathrm{~b}$ & $34.9 \mathrm{a}$ & $49.9 \mathrm{a}$ & $51.9 \mathrm{~b}$ & $35.0 \mathrm{a}$ \\
F44 & $3.1 \mathrm{c}$ & $7.0 \mathrm{c}$ & $33.6 \mathrm{c}$ & $48.2 \mathrm{~b}$ & $54.2 \mathrm{a}$ & $26.3 \mathrm{~d}$ \\
F125 & $8.1 \mathrm{a}$ & $12.0 \mathrm{a}$ & $34.2 \mathrm{~b}$ & $44.0 \mathrm{~d}$ & $40.7 \mathrm{~d}$ & $15.1 \mathrm{e}$ \\
F127 & $0.8 \mathrm{~d}$ & $6.1 \mathrm{~d}$ & $29.0 \mathrm{e}$ & $42.1 \mathrm{e}$ & $45.0 \mathrm{c}$ & $30.5 \mathrm{~b}$ \\
F156 & $3.7 \mathrm{~b}$ & $6.9 \mathrm{c}$ & $32.5 \mathrm{~d}$ & $46.2 \mathrm{c}$ & $52.7 \mathrm{~b}$ & $29.1 \mathrm{c}$ \\
\hline
\end{tabular}

${ }^{\mathrm{z}}$ Values represent the means of 12 replications for each isolate at each temperature. Means followed by the same letter are not significantly different according to Duncan's multiple range test $(P=$ 0.05 ).

tem using one emitter per tube and watering the soil to saturation, approximately 1 liter after 5 to 10 min duration.

Data collection. After 6 weeks, plants were removed from the tubes and rinsed of 0 to 4 was performed as previously described for Fusarium root rot (11). Briefly, the rating system was as follows: $0=$ no disease, $1=$ less than $25 \%$ of vascular ele$2=26$ to $50 \%$ vascular necros than $10 \%$ of taproot rotted, $3=$ over $50 \%$ necrosis of vascular elements and 10 to $25 \%$ of taproot rotted, and $4=$ more than crown and foliage) were removed and dried separately from roots in paper bags in a soil-drying oven at 55 to $60^{\circ} \mathrm{C}$. After 2 to 3 days, root and top dry weights were recorded. This experiment was repeated

All data were subjected to the general linear model procedure. Treatment means were separated by Duncan's multiple range test, and variance between the two tests analysis was also used to determine the relationship between root disease rating and foliar and root dry weights.

\section{RESULTS}

Radial growth at different temperatures. Results of growth studies are predifferences between isolates and their abilities to grow in culture at different temperatures. F125 grew best at lower temperatures, and growth was greatly reduced as temperatures exceeded $25^{\circ} \mathrm{C}$. It reached its maximum growth at $25^{\circ} \mathrm{C}$, while the other four did so at $30^{\circ} \mathrm{C}$ (Table

1040 Plant Disease / Vol. 82 No. 9
2). Above $30^{\circ} \mathrm{C}$, all isolates were inhibited, but not as dramatically as F125. This agrees with most reports that $F$. oxysporum has optimum growth temperatures in the range of 25 to $28^{\circ} \mathrm{C}$. It is interesting to note that three of the four remaining isolates that grew better at higher temperatures were members of the same VCG, whereas F125 was in a separate one (Tables 1 and 2). The self-incompatible isolate (F5) had the greatest growth among isolates after 8 days at $35^{\circ} \mathrm{C}$, but not at $30^{\circ} \mathrm{C}$. (Table 2).

Virulence evaluations at two temperatures and irrigation schedules. Variance between replicated tests was homogenous, and no treatment-test interactions were observed. Additionally, no differences from the two irrigation treatments were observed for root rot severity on the inoculated sugar beets. Both high and low levels of water applied during the experiment resulted in equivalent levels of disease (data not shown). Therefore, all data from both tests were combined to include 24 replications per isolate for each of the two temperature box treatments. However, there were large differences between the two temperatures evaluated, with significantly higher disease ratings at $30^{\circ} \mathrm{C}$ than at $20^{\circ} \mathrm{C}$ (Tables 3 and 4). Although all isolates had previously been determined to be pathogenic at ambient greenhouse temperatures of 25 to $30^{\circ} \mathrm{C}$, (12), only F5 caused significantly higher disease ratings at $20^{\circ} \mathrm{C}$ than the uninoculated control. At this temperature, the remaining four isolates were essentially nonpathogenic. Plant dry weights did not correlate well with disease rating for any of the isolates except $\mathrm{F} 44$ at $20^{\circ} \mathrm{C}$. (Table $3)$.

At $30^{\circ} \mathrm{C}$, three isolates (F5, F127, and F156) caused severe damage to beet roots (Table 4). These were originally tip rot isolates collected from the field, and all three reproduced this symptom on plants at this temperature in the greenhouse. F125 was a non-tip rot isolate and produced moderate disease levels but no tip rot symptom. F44, although belonging to the same VCG as F127 and F156, produced mild symptoms that were statistically nonsignificant from the control. Like F125, F44 was a non-tip rot isolate and produced only a slight discoloration of several of the vascular elements in roots, but no tip rot. At $30^{\circ} \mathrm{C}$, there was a significant negative correlation between disease rating and dry weight (Table 4).

\section{DISCUSSION}

It is surprising that such radical differences were observed among $F$. oxysporum f. sp. betae isolates in terms of growth at different temperatures in culture (Table 2). Although all isolates were considered to be pathogenic under greenhouse conditions from previous evaluations (12), significant differences among isolates occurred at all six temperatures evaluated. However, these 
growth differences did not correspond to differences in virulence among the same isolates at 20 and $30^{\circ} \mathrm{C}$.

Results of this experiment demonstrate that irrigation had no effect upon disease severity. This may possibly be explained by early infection soon after transplantation, since all tubes were watered equally at the initiation of the experiment. If the low-water treatment plants were already infected, perhaps the lack of any additional irrigation would not affect further disease development. Previous studies on soil moisture and its influence on Fusarium disease severity have produced contradictory results. Most studies conclude that Fusarium wilts are favored by wet soil, presumably because Fusarium disease progression depends upon movement of microconidia in the xylem after it enters the host $(4,5)$. Conditions that slow transpiration, such as dry soil, are thought to also slow conidial transport up the stem (4). However, some earlier studies contradict these findings and report that severity of Fusarium wilt of tomato, cabbage, and spinach was higher following hot, dry weather, with little or no disease following cool, moist conditions $(3,14,24)$. To our knowledge, this is the first report of a Fusarium disease not influenced by soil moisture.

Very little root damage occurred at $20^{\circ} \mathrm{C}$, except for that produced by $\mathrm{F} 5$, but disease severity was much greater for all isolates at $30^{\circ} \mathrm{C}$ (Tables 3 and 4). This phenomenon of enhanced disease expression and severity at higher temperatures has been reported for Fusarium wilt of cabbage $(2,24)$, tomato (3), and chrysanthemum (9). Although three isolates produced severe damage to plants at $30^{\circ} \mathrm{C}$, it was unexpected that such substantial differences would exist in virulence among these isolates that were known to be pathogenic to sugar beet (Table 4).

It is interesting to note that the differences in virulence were not correlated with the different vegetative compatibility groupings or hosts from which isolates were collected. Pigweed (F125 and F156) and sugar beet isolates (F5, F44, and F127) both produced mild to moderate and severe symptoms at $30^{\circ} \mathrm{C}$ (Table 4). VCG 1 also was represented by both mild and severe symptom-inducing isolates (Tables 1 and 4). F125, representing VCG 6, grew better than the others in vitro at lower temperatures, but it was not pathogenic at $20^{\circ} \mathrm{C}$ and was only moderately virulent at $30^{\circ} \mathrm{C}$. It should also be pointed out that the most severe isolate at both temperatures (F5) was self-incompatible and could not be placed in a VCG.

Correlation coefficients for root disease ratings and plant dry weights, except for that of $\mathrm{F} 44$, were nonsignificant at $20^{\circ} \mathrm{C}$ (Table 3). This shows that pathogenicity at this temperature was negligible for most isolates. Although F5 was pathogenic at this temperature, as indicated by a disease rating of 2 , there was little effect on plant growth. This phenomenon has been observed before in both field and greenhouse studies (10). Often, if conditions favoring plant growth predominate over those favoring pathogen development later in the season, a beet may recover by producing small feeder roots. This allows enough root growth to support a deceptively healthy foliage system, even though total root yield and taproot size are reduced (10). This same relationship is seen with isolate F127 in its nonsignificant disease correlation to foliar dry weight at $30^{\circ} \mathrm{C}$ (Table 4).

All isolates except F44 were collected from fields with long histories of sugar beet production. F44 was isolated from a field cropped to sugar beets for the first time. Its presence in this field could be explained by an introduction on sugar beet seed, since $F$. oxysporum f. sp. betae has been demonstrated to be seedborne (17). However, this is unlikely because it was not vegetatively compatible with any isolates from Oregon (12), the location where all U.S. sugar beet seed is increased. It is also possible that it was native to Texas soils, surviving on pigweed or some other weed (18). Windels and Kommedahl (27) similarly identified large populations of $F$. oxysporum from virgin prairie soils in Minnesota.

Table 3. Root disease ratings, root and top dry weights, and disease correlations with plant dry weights from sugar beet after inoculation with Fusarium oxysporum f. sp. betae isolates and incubated at $20^{\circ} \mathrm{C}$ for 6 weeks ${ }^{\mathrm{v}}$

\begin{tabular}{lllclc}
\hline Isolate & $\mathbf{D R}^{\mathbf{w}}$ & $\mathbf{R D W}^{\mathbf{x}}$ & $(\boldsymbol{r})^{\mathbf{y}}$ & FDW $^{\mathbf{z}}$ & $(\boldsymbol{r})$ \\
\hline F5 & $2.0 \mathrm{a}$ & $2.6 \mathrm{c}$ & 0.28 & $6.4 \mathrm{ab}$ & -0.32 \\
F44 & $0.2 \mathrm{~b}$ & $3.3 \mathrm{bc}$ & $-0.67^{*}$ & $6.8 \mathrm{a}$ & $-0.55^{*}$ \\
F125 & $0.3 \mathrm{~b}$ & $3.5 \mathrm{bc}$ & 0.21 & $5.8 \mathrm{ab}$ & 0.03 \\
F127 & $0.4 \mathrm{~b}$ & $3.2 \mathrm{bc}$ & -0.05 & $6.3 \mathrm{ab}$ & -0.32 \\
F156 & $0.4 \mathrm{~b}$ & $4.0 \mathrm{ab}$ & 0.29 & $5.8 \mathrm{~b}$ & -0.11 \\
Control & $0.0 \mathrm{~b}$ & $4.9 \mathrm{a}$ & $\ldots$ & $6.4 \mathrm{ab}$ & $\ldots$ \\
Cumulative & $\ldots$ & & -0.21 & & 0.08 \\
\hline
\end{tabular}

${ }^{v}$ Values represent the mean of 24 replications for each isolate. Means in a column followed by the same letter are not significantly different according to Duncan's multiple range test $(P=0.05)$.

${ }^{\mathrm{w}}$ Root disease rating (0 to 4$)$.

${ }^{\mathrm{x}}$ Root dry weight $(\mathrm{g})$.

y Correlation coefficient; $*$ significant $(P=0.05)$

${ }^{\mathrm{z}}$ Foliar dry weight $(\mathrm{g})$.

Table 4. Root disease ratings, root and top dry weights, and disease correlations with plant dry weights from sugar beet after inoculation with Fusarium oxysporum f. sp. betae isolates and incubated at $30^{\circ} \mathrm{C}$ for 6 weeks

\begin{tabular}{lccccc}
\hline Isolate & $\mathbf{D R}^{\mathbf{w}}$ & RDW $^{\mathbf{x}}$ & $(\boldsymbol{r})^{\mathbf{y}}$ & FDW $^{\mathbf{z}}$ & $(\boldsymbol{r})$ \\
\hline F5 & $3.5 \mathrm{a}$ & $1.3 \mathrm{~b}$ & $-0.72^{*}$ & $2.2 \mathrm{c}$ & $-0.79^{*}$ \\
F44 & $0.7 \mathrm{c}$ & $5.1 \mathrm{a}$ & $-0.60^{*}$ & $8.8 \mathrm{a}$ & $-0.58^{*}$ \\
F125 & $1.7 \mathrm{~b}$ & $4.1 \mathrm{a}$ & $-0.90^{*}$ & $7.6 \mathrm{a}$ & $-0.70^{*}$ \\
F127 & $2.4 \mathrm{~b}$ & $2.0 \mathrm{~b}$ & $-0.75^{*}$ & $4.8 \mathrm{~b}$ & -0.36 \\
F156 & $3.3 \mathrm{a}$ & $1.5 \mathrm{~b}$ & $-0.66^{*}$ & $4.4 \mathrm{~b}$ & $-0.66^{*}$ \\
Control & $0.0 \mathrm{c}$ & $4.7 \mathrm{a}$ & $\ldots$ & $8.5 \mathrm{a}$ & $\ldots$ \\
Cumulative & & & $-0.78^{*}$ & & $-0.74^{*}$ \\
\hline
\end{tabular}

${ }^{v}$ Values represent the mean of 24 replications for each isolate. Means in a column followed by the same letter are not significantly different according to Duncan's multiple range test $(P=0.05)$

${ }^{\text {w }}$ Root disease rating (0 to 4 ).

${ }^{\mathrm{x}}$ Root dry weight (g).

y Correlation coefficient; $*=$ significant $(P=0.05)$.

${ }^{\mathrm{z}}$ Foliar dry weight (g).
The most significant result from this
study was that neither water nor temperature changed symptom phenotypes for the five isolates evaluated. The three tip rot greatest amount of disease at $30^{\circ} \mathrm{C}$ and also reproduced the same root rot symptom in strated in the field. Only F5 induced a tip at $20^{\circ} \mathrm{C}$. The non-tip rot isolates ( $\mathrm{F} 44$ toms at either temperature. This suggests causing different symptoms (diseases), and that symptom phenotype is not a result of tenvironmental conditions.

among $F$. oxysporum isolates have been (6,7,20), single-member VCGs are representative of variation within forspeciales. Another study compared caused different symptoms on potatoes by compatibility. Although sympisolates, several isolates causing a specific the results of our study, because representatives of both symptom types from sugar 
beet were found to belong to the same VCG (Table 1; 12)

The traditional sugar beet vascular wilt disease, Fusarium yellows, was first reported from Colorado (23); however, no mention of external root symptoms was made. No subsequent reports of this disease have included a description of root rot symptoms until the first report from Texas in 1989 (19). In Texas, root rot is still the primary symptom observed. The evidence obtained involving genetic and pathogenic characteristics of $F$. oxysporum f. sp. betae isolates from Texas and other sugar beetproducing states suggests that Texas root rot isolates are different and may warrant a distinct forma specialis to reflect this root rot symptom (19).

Snyder and Hansen's classification scheme designates $F$. oxysporum by the form name of the host (22). A number of studies have been conducted concerning several different root rot diseases caused by $F$. oxysporum where the form name has previously been used to designate the organism as a wilt pathogen on that host. In cases like this, Weimer suggested using a different form name to reflect the root rot symptom (26). Examples of this include $F$. oxysporum $\mathrm{f}$. $\mathrm{sp}$. radicis-lupini, causing a wilt and root rot of lupines (26), and $F$. oxysporum f. sp. radicis-lycopersici, causal agent of root and crown rot of tomato (16). However, several additional Fusarium oxysporum root rot diseases have also been reported without assigning a special forma specialis designation for the pathogen, including a root rot of Douglas fir seedlings and a wilt and root rot of spinach $(1,14)$.

Previous studies have demonstrated substantial differences between $F$. oxysporum f. sp. betae isolates from the United States and those causing root rot in Texas $(8,12,19)$. The results from this study have further shown that environmental conditions (temperature and moisture) do not change symptom phenotypes for Texas isolates. Therefore, we propose that the tip rot isolates from Texas be designated $F$. oxysporum f. sp. radicis-betae, in accordance with previously suggested protocol $(16,19,26)$, to represent $F$. oxysporum isolates causing root rot symptoms on sugar beet.

\section{LITERATURE CITED}

1. Bloomberg, W. J. 1973. Fusarium root rot of Douglas-fir seedlings. Phytopathology 63:337-341.

2. Bosland, P. W., Williams, P. H., and Morrison, R. H. 1988. Influence of soil temperature on the expression of yellows and wilt of crucifers by Fusarium oxysporum. Plant Dis. 72:777-780.

3. Clayton, E. E. 1923. The relation of soil moisture to the Fusarium wilt of tomato. Am. J. Bot. 10:133-147.

4. Cook, R. J. 1981. Water relations in the biology of Fusarium. Pages 236-244 in: Fusarium: Diseases, Biology, and Taxonomy. P. E. Nelson, T. A. Tousson, and R. J. Cook, eds. Pennsylvania State University, University Park.

5. Cook, R. J., and Papendick, R. I. 1972. Influence of water potential of soils and plants on root disease. Annu. Rev. Phytopathol. 10:349372.

6. Elias, K. S., and Schneider, R. W. 1991. Vegetative compatibility groups in Fusarium oxysporum f. sp. lycopersici. Phytopathology 81:159-162.

7. Elmer, W. H., and Stephens, C. T. 1989. Classification of Fusarium oxysporum f. sp. asparagi into vegetatively compatible groups. Phytopathology 79:88-93.

8. Fisher, G. A., and Gerik, J. S. 1994. Genetic diversity of Fusarium oxysporum isolates pathogenic to sugar beets. (Abstr.) Phytopathology 84:1098

9. Gardiner, D. C., Horst, R. K., and Nelson, P. E. 1987. Symptom enhancement of Fusarium wilt of chrysanthemum by high temperatures. Plant Dis. 71:1106-1109.

10. Harveson, R. M., and Rush, C. M. 1993. An environmentally controlled experiment to monitor the effect of Aphanomyces root rot and rhizomania on sugar beet. Phytopathology 83:1220-1223.

11. Harveson, R. M., and Rush, C. M. 1994. Evaluation of fumigation and rhizomania-tolerant cultivars for control of a root disease complex of sugar beets. Plant Dis. 78:11971202.

12. Harveson, R. M., and Rush, C. M. 1997. Genetic variation among Fusarium oxysporum isolates from sugar beet as deter- mined by vegetative compatibility. Plant Dis 81:85-88.

13. Harveson, R. M., Rush, C. M., and Kistler, H. C. 1997. Biological characterization of Fusarium oxysporum isolates pathogenic to sugar beet. (Abstr.) Phytopathology 87:S40.

14. Hungerford, C. W. 1923. A Fusarium wilt of spinach. Phytopathology 13:205-209.

15. Jacobson, D. J., and Gordon, T. R. 1988 Vegetative compatibility and self-incompatibility within Fusarium oxysporum f. sp. melonis. Phytopathology 78:668-672.

16. Jarvis, W. R., and Shoemaker, R. A. 1978. Taxonomic status of Fusarium oxysporum causing foot and root rot of tomato. Phytopathology 68:1679-1680.

17. MacDonald, J. D., and Leach, L. D. 1976. The association of Fusarium oxysporum f. sp. betae with nonprocessed and processed sugarbeet seed. Phytopathology 66:868-872.

18. MacDonald, J. D., and Leach, L. D. 1976. Evidence for an expanded host range of Fusarium oxysporum f. sp. betae. Phytopathology 66:822-827.

19. Martyn, R. D., Rush, C. M., Biles, C. L., and Baker, E. H. 1989. Etiology of a root rot disease of sugar beet in Texas. Plant Dis. 73:879884.

20. Ploetz, R. C. 1990. Variability in Fusarium oxysporum f. sp. cubense. Can J. Bot. 68:1357-1363.

21. Rush, C. M., and Kraft, J. M. 1986. Effects of inoculum density and placement on Fusarium root rot of peas. Phytopathology 76:13251329.

22. Snyder, W. C., and Hansen, H. N. 1940. The species concept in Fusarium. Am. J. Bot. 27:64-67.

23. Stewart, D. 1931. Sugar-beet yellows caused by Fusarium conglutinans var. betae. Phytopathology 21:59-70.

24. Tisdale, W. B. 1923. Influence of soil temperature and soil moisture upon the Fusarium disease in cabbage seedlings. J. Agric. Res. 24:55-86

25. Venter, S. L., Theron, D. J., Steyn, P. J., Ferreira, D. I., and Eicker, A. 1992. Relationship between vegetative compatibility and pathogenicity of isolates of Fusarium oxysporum $\mathrm{f}$. sp. tuberosi from potato. Phytopathology 82:858-862.

26. Weimer, J. L. 1944. Some root rots and a foot rot of lupines in the southeastern part of the United States. J. Agric. Res. 68:441-457.

27. Windels, C. E., and Kommedahl, T. 1974 Population differences in indigenous Fusarium species by corn culture of prairie soil. Am. J. Bot. 61:141-145. 